\title{
LA CULTURA DEL OCIO
}

\author{
RAMON MARTIN MATEO \\ Catedrático de Derecho Administrativo y Rector de la Universidad de Alicante
}

\section{CARACTERES}

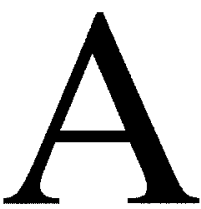

unque todos tenemos más o menos claro lo que es el ocio, las satisfacciones que comporta, y las circunstancias que lo hacen posible, creo que es conveniente indagar críticamente sus contornos e identificar aquellos de sus rasgos que le hacen socialmente relevante, para deducir a la postre las respuestas que desde los poderes públicos pueden o deben darse ante un fenómeno que se traslada al plano de los intereses generales.

La percepción individual del ocio coincide sustancialmente con la colectiva, aunque hay zonas conceptuales, no secantes, que cambian de sujeto a sujeto, que no interesan desde la óptica aquí seguida, que sólo contempla los grandes agregados políticamente transcendentes.

\section{Dimensión pasiva-biológica}

Mucha gente cree que ocio es fundamentalmente no hacer nada, simplemente descansar con la mente vacía, dormir, o relajarse al sol.

Esta comprensión enlaza con algo que tiene una relación menor con el ocio cultural, me refiero a las relaciones trabajo-descanso, procesos explicables desde la perspectiva física con base en la segunda ley de la termodinámica y en la generación de entropía, pero que sobre todo tiene natural encaje en la dinámica de la biología que justifica la necesidad del descanso que afecta a todos los organismos vivos, simples o complejos, para el desempeño de las funciones que genéticamente tienen asignadas dosificando la energía necesaria.

Esta función fisiológica del ocio no carece, para nuestra especie, de transcendencia social y así en el pasado siglo se impuso ya el disfrute de descansos diarios o periódicos, a impulsos de las organizaciones de trabajadores, acortándose después progresivamente la jornada laboral. Lo que en los comienzos del industrialismo respondía a planteamientos crudamente primarios, dio entrada después a la intercalación de períodos no trabajados, con criterios ya correspondientes al ocio cultural. 
Esta última dimensión, aquí abordada, también luce en lo que pudiéramos calificar como simple inacción. El disfrute del ocio activo incluye también necesariamente un generoso espacio para las funciones vitales: prolongación del descanso nocturno, siesta estival, incluso lo que puede parecer próximo al nirvana, el dormitar en un sillón del porche o la somnolencia en una playa veraniega, implican sensaciones somáticas y vivencias mentales a la vez, que son propias del concepto estricto de ocio que intentamos desarrollar.

\section{Comprensión activa-psicológica}

El ocio sale del campo de la necesidad para pasar al del placer. Aunque las sensaciones que determina sean meros impulsos bioquímicos, sus componentes no son estrictamente materiales, están relacionados con los dominios de la mente y los mecanismos psicológicos.

Por tanto, una misma actividad puede suponer una enorme satisfacción o una cruel angustia, según lo que se perciba por el sujeto afectado. Levantar pesos no es igual para el que practica la alterofilia que para el condenado a trabajos forzados; no disfrutan lo mismo el serpa que el alpinista; descansar inmóvil en la cama es una horrible tortura para el ocupante de una «cárcel del pueblo».

Esta comprensión lúdico-individual del ocio me parece imprescindible pero no definitiva para la identificación del ocio cultural, que se practica en grupo.

Los animales también tienen acceso a este tipo de disfrutes elementales; posiblemente los gorjeos de las aves y sus revoloteos aparentemente sin sentido, lo que pudiera ser trasladable a los insectos, caso de las cigarras, tienen también una justificación recreativa.

Desde luego es puro juego el clásico debate del gato con el ovillo, o las carreras emulativas de los perros y los caballos. Algunos animales cazadores matan más presas de las que necesitan si éstas abundan y no tienen necesidad por tanto de dosificar sus energías; recordemos las masacres de ovejas por lobos o perros asilvestrados.

\section{La ausencia de negocio}

Expresivamente se califica la actividad económica como la negación del ocio; para que se dé este último es preciso que no se obtengan resultados trasladables al mercado.

Al igual que sucede con la incidencia del componente sicológico, una misma actividad puede ser lúdico-gratuita $\mathbf{u}$ onerosa-retribuida; lo mismo hacen los componentes de los equipos de fútbol profesionales que disputan un partido de fútbol y los aficionados, pero la ca- 
lificación es distinta en un caso y en otro, en el primero se ejerce un oficio retribuido y en el otro es pura diversión.

$\mathrm{El}$ talante con que se asumen tareas de signo productivo no trasciende a su enjuiciamiento en términos de ocio o de negocio; lo importante son las consecuencias económicas para el agente, que en un caso ve incrementado su patrimonio y en el primero no.

Es sin embargo falsa la comprensión, de origen bíblico, del trabajo como maldición, como carga insoportable, lo que a veces es asumido literalmente por las organizaciones de trabajadores que tenazmente persiguen, parece que por cuestión de principios, la reducción de la jornada laboral, lo que paradójicamente pretenden por cierto también, globalmente, los empresarios que intentan sustituir horas de trabajo por nuevas tecnologías.

Posiblemente todos los futbolistas del ejemplo anterior se diviertan en su empeño, quizás más unos que otros, y en general hoy muchos trabajadores, oficinistas, o empleados, que se encuentran a gusto en su centro de trabajo, que comparan a veces positivamente con las tediosas tareas de su domicilio, aunque posiblemente no lo confesarían al encuestador.

Personalmente estimo que el mejor día de la semana es el lunes, aunque me encuentre muy a gusto en el seno de la familia. Hay una expresión anglosajona que identifica a los que en el extremo de esta propensión, están obsesionados por sus tareas profesionales: workoholics, son personas que parecen efectivamente intoxicadas por el trabajo, que prolongan voluntariamente la jornada, reducen los fines de semana y alardean de no disfrutar de vacaciones.

Pues bien, aunque la motivación profunda de la actividad laboral o profesional no sea el lucro, no estamos evidentemente en estos casos en presencia del ocio, sino de negocio, por lo que no serán extensibles a estos supuestos las consideraciones que más adelante abordamos.

\section{El hecho social}

Aunque pueden aparecer manifestaciones puramente individuales del ocio tal comportamiento es excepcional; un eremita o un crapuloso solitario no son representativos de los comportamientos aquí implicados.

El hombre es un animal gregario y es por tanto lógico que estas actividades, sobre todo en cuanto que dejan un amplio ámbito a las relaciones del mismo sentido, se realicen en grupo, que será familiar sobre todo pero también suprafamiliar incluyendo amigos, o conciudadanos, adquiriendo más allá aún signo territorial: comunidades campesinas, barrios urbanos, ciudades, regiones y naciones. 
Esto no es una novedad, siempre ha sido así como atestiguan las pinturas rupestres y la temprana incidencia de las religiones que sacralizaron para el reposo determinados días del año o de la semana con períodos más amplios dedicados a festejos religiosos, civiles, o mixtos.

\section{La recepción institucional}

Si el ocio es un hecho social, es lógico que transcienda a las organizaciones que paulatinamente se van haciendo cargo de la satisfacción de necesidades colectivas.

Desde los orígenes de la humanidad parece que el jefe del grupo o de tribu que se encargaría de convocar, esporádicamente primero y periódicamente después, determinadas celebraciones tempranamente ritualizadas pero que incluían también bailes y regocijos y consumos extraordinarios en común de bebidas y alimentos.

Al dotarse de más estabilidad lo religioso, con apoyo de servidores profesionales del culto en las primitivas teocracias o de incipientes estructuras políticas más adelante, se impuso políticamente la no laboralización de determinadas jornadas y la institucionalización de disfrutes colectivos. La organización de las fiestas patronales se incluye desde siempre entre las competencias de los regidores de los asentamientos rurales, lo que por supuesto se sigue manteniendo en todos los municipios o equivalentes del mundo con mayor o menor amplitud.

Otros grupos intermedios de carácter profesional, como los gremios y las corporaciones medievales, tenían una gran proclividad en cuanto a la celebración de grandes festejos, con el apoyo logístico de catedrales, iglesias y capillas, en los que se honraba al santo patrón.

Instancias superiores precedentes de los actuales Estados, también desempeñaron responsabilidades de este tenor; recordemos las peregrinaciones hacia los santuarios helénicos y ya establemente los espectáculos implantados en los coliseos romanos. La política de «pan y circo» puede constituir un antecedente de la actual civilización del ocio.

En la Edad Media, reyes, príncipes y señores feudales, ofrecían al pueblo justas, torneos, corridas de toros y otro tipo de espectáculos, a veces alumbrados con el fuego de las hogueras en que se quemaban herejes y grandes delincuentes, se implicaba al pueblo en celebraciones relacionadas con nupcias y efemérides reales, visitas principescas y reuniones de Cortes.

Los Estados contemporáneos recogen este testigo aunque su aportación tendrá un sentido distinto al canalizarse a través de los cauces habituales de la gestión burocrática. 


\section{La impronta civilizatoria}

El ocio ha constituido en los tiempos pasados un componente más bien reducido de la vida social, pese a que en ocasiones culturas como la de Roma o Bizancio hayan motorizado importantes iniciativas públicas y arbitrado complejos equipamientos.

Pero hay que esperar a la Segunda Guerra Mundial para detectar un poderoso movimiento impulsado por la técnica y la política, que va a acentuar la importancia de las actividades no productivas destinadas al descanso y recreo, haciendo emerger una auténtica cultura del ocio, lo que quizás sea el rasgo más significativo del tipo de civilización que vivimos en esta época histórica, en el mundo occidental al menos, es decir en el amplio grupo que hoy detenta el protagonismo de la Historia, si bien dentro de él las gratificaciones que proporciona este tipo de cultura afectan con escasa incidencia, como puede sospecharse, a ciertos colectivos como los desempleados, marginales y menesterosos.

A otra escala se aprecia la paradójica convivencia del opulento Norte y la pobreza de un Sur que no sólo no ha podido llegar a la generalización de estas satisfacciones, sino que frecuentemente no está en condiciones de garantizar la supervivencia física de muchos de sus componentes, lo que debe hacer reflexionar sobre la viabilidad de mantener planetariamente tan disparatadas situaciones.

La prosperidad que ha hecho posible el acortamiento de las horas laborales, se ha debido a la eficacia racionalizadora del mercado, pero sobre todo a los progresos del conocimiento. Las nuevas tecnologías han irrumpido con vigor en el sistema productivo, ampliando fabulosamente los resultados obtenibles de la energía humana. Pero el progreso económico y el incremento de los beneficios ya no suponen el aumento de plantilla sino posiblemente su restricción, al permitir los ahorros deparados por una buena coyuntura empresarial invertir en innovaciones productivas que suprimen puestos de trabajo.

Este fenómeno ha tenido una aparatosa influencia en la agricultura, que ha pasado a ser un sector económico minoritario, pese a que no hace muchos años generaba el grueso del PIB.

No hay posibilidad de retroceder hacia un pasado artesanal y bucólico; inexorablemente el progreso supondrá a escala empresarial la minoración de operarios. Las soluciones vendrán seguramente de la mano de nuevas macropolíticas y de mutaciones éticas que afectarán comportamientos colectivos, en lo que no vamos a entrar.

El proceso ha venido siendo eficazmente impulsado por las organizaciones sindicales cuyos programas reivindicativos acusan la inercia de las situaciones propias de las primera etapas del industrialismo. La presión sobre la mayoría de los niveles retributivos y 
paralelamente por el acortamiento de las horas trabajadas, ha incentivado el modificar los procesos para obtener mayores rentabilidades por empleado.

Otro dato a tener en cuenta es el incremento de la esperanza de vida como consecuencia de los avances nutricionales y sobre todo sanitarios, que ha hecho reforzar un sector de población que apenas tenía entidad no hace mucho tiempo, el de los jubilados activos en perfecta forma física hoy demandadores de prestaciones.

La Administración que antes apenas prestaba atención a este colectivo se ha visto obligada a intervenir, incentivada por la clase política que detecta aquí, con razón, un grupo cohesionado de votantes altamente motivados.

Se renuevan así una serie de servicios anteriormente entregados a la beneficiencia, pero que hoy se engarzan sólidamente en la red de las prestaciones públicas sociales, como las residencias para las personas mayores.

Otros dispositivos son de reciente creación: organizaciones de viajes recreativos, de festivales y esparcimientos, promoción de asociaciones y de actividades en grupo, financiación de clubs de tercera edad, patrocinio de orfeones, campeonatos de juegos, visitas culturales, etc.

\section{Una revolución en curso}

La relevancia del ocio como elemento significativo de la vida social ha sido reconocida en la propia Constitución Española que en su artículo 43.3 ordena a los poderes públicos facilitar «la adecuada utilización del ocio» garantizándose a los ciudadanos durante la tercera edad la promoción de su bienestar, «mediante un sistema de servicios sociales que atenderán sus problemas específicos de salud, vivienda, cultura y ocio» ${ }^{1}$.

La mayoría de nuestros contemporáneos no habrán parado mientes en los caracteres, auténticamente transtocadores, del sistema socieconómico precedente, que ha supuesto el que el ocio surja como actividad singular que no está ligada necesariamente a requerimientos biológicos ni es mera secuela de la relación de trabajo. El ocio, en su sentido positivo por supuesto, que pasa a informar la zona clave de los dictados políticos, hace que la Administración se movilice de acuerdo con sus exigencias, más allá de una respuesta mimética a las demandas sociales como cumplimiento de estrictos imperativos constitucionales.

Todo esto era escasamente visualizable hace algunas décadas. Cuando el medio rural albergaba y comprendía el sector mayoritario en efectivos activos de la economía española, no había allí más in-

1 Artículo 50. 
terrupciones del trabajo que lo que suponían los domingos y las contadas fiestas civiles y religiosas. Durante las tareas de la recolección, en Castilla al menos, ni siquiera se respetaba el descanso semanal, el día de la Virgen de agosto era el único oasis veraniego de ocio. En estas épocas la jornada empezaba poco después de medianoche, con un alto para la siesta. En todo el año el horario de trabajo se regía por la meteorología y el calendario solar.

La incorporación a las labores agrícolas se iniciaba, en el mejor de los casos, al acabar las primeras letras y la salida se producía cuando fallaban las fuerzas físicas. La carga económica para las rudimentarias instituciones sociales era escasa, la vida duraba poco más que el inicio efectivo de la jubilación.

En la actualidad todo ha cambiado, felizmente. En el campo las condiciones siguen siendo más duras si bien la población ha disminuido drásticamente y en la ciudad apenas se dedica al trabajo, si se consigue, uno varios puestos sucesivos de carácter permanente, aproximadamente el $50 \%$ de la vida de una persona, correspondiendo el resto a los períodos de formación, desarrollo y aprendizaje y al disfrute de la jubilación.

La semana laboral no excede de 40 horas, y además múltiples días de fiesta civiles y religiosos y paréntesis más amplios integrados por «puentes», vacaciones cortas: Navidad, Semana Santa, y largas, verano, reducen sustancialmente el calendario laboral.

Debemos congratularnos de que esto sea así y que vaya a mejorar incluso. Las tendencias apuntan, al margen de otros factores y en condiciones de normalidad económica, a la distribución de la vida de un sujeto en tres períodos: prelaboral-laboral-postlaboral, en el que el activo no será el predominante.

Es previsible a medio plazo el acortamiento del tramo central en beneficio de los otros dos, especialmente del último. No estamos quizás en presencia de una crisis coyuntural, sino estructural en la que la disminución de empleos se debe en Occidente a las siguientes causas:

- Incremento de la productividad tecnológica sobre todo en los países desarrollados.

- Desplazamiento paulatino de la provisión de bienes que implican mano de obra no cualificada hacia los países en trance de desarrollo.

- Cambio tendencial de los hábitos de consumo en un sentido cualitativo.

A largo plazo, hacia mediados de la próxima centuria no habrá motivos de preocupación; los nuevos descubrimientos y la puesta en aplicación de los ya disponibles: energía nuclear de fusión, biotecnología, garantizarán recursos en abundancia, incluso para los países no desarrollados. 
En el ínterin se pueden producir desajustes perturbadores hasta tanto no se equilibren los segmentos de población joven y de tercera edad, lo que posiblemente impondrá con carácter transitorio la prolongación de la edad de jubilación y el incremento de la presión fiscal sobre la población activa.

Puede parecer paradójico y aún cruel este prolongado discurso sobre el ocio, cuando en este momento en todo el mundo y especialmente en España, millones de personas han sido expulsadas del mundo del trabajo; pero hay aquí además del componente económico indudable, una solución pendiente, a la postre política, institucional; de ahí los riesgos derivados de la falta de flexibilidad y adecuación tanto de los órganos de gobierno tradicionales como de las organizaciones sociales privadas aquí incidentes, a las cambiantes circunstancias científico-técnicas que han inducido la revolución del ocio, bienvenida sea por cierto. 